\title{
Oral health of adults in northern Norway - A pilot study
}

\author{
Sarah M. Adekoya and Magritt Brustad \\ Centre for Sami Health Research, Institute of Community Medicine, University of Tromsø, Norway \\ Correspondence: Sarah M. Adekoya, Centre for Sami Health research, Institute of Community Medicine, 9037 Troms $\varnothing$ \\ E-mail:sarahadekoya@hotmail.com
}

\begin{abstract}
There is a deficiency of data on oral health of adults in northern Norway, and available reports indicate poorer oral health in the north as compared with the rest of the country. The objective of this pilot study was to develop and test out tools for a larger epidemiological study of oral health among adults in northern Norway. The study was conducted in the municipalities of Nordkapp and Båtsfjord located in the northernmost county, Finnmark. Questionnaires and letters of invitation were sent to 100 randomly selected individuals in each town, in total 200. Those who filled and returned the questionnaires were sent appointment cards to a free oral examination at the local dental clinic. The main finding from the study was a low response rate; $34 \%$ responded to the questionnaire and $26.5 \%$ attended the oral examination. Response rate was highest among women above forty years old (37\%) and lowest among men under forty years (12\%). There is a necessity for further studies and strategies to increase response rate to subsequent oral epidemiologic studies in northern Norway. Radiological examination is not necessary for such studies but a questionnaire and a physical oral examination should be included.
\end{abstract}

\section{BACKGROUND}

Oral health is an important aspect of general health and well-being for both children and adults [1]. In Norway the state-supplied oral health service and municipality-state reporting system (KOSTRA) ensures a constant access to oral health data for children and adolescents, but there is a deficiency of scientifically acquired information on the oral health status of the adult population, particularly in the northern parts of the country [2].

Reports from National Bureau of Statistics (SSB) have consistently reported a poorer oral health status in the 3 northernmost counties [2], worst being the county of Finnmark and especially in some of the communities with a large proportion of indigenous Sami population. Finnmark is an area with low population density (a population of 1.5 persons per $\mathrm{km}^{2}$ ) and historically, a low dentist density (DD = population/dentist). The White Paper Accessibility, competence and equalization - The future dental service specifically mentions (chapter 5.2.2) the poorer dental health situation of the Sami population in northern Norway as compared to the rest of the population [3]. The same document (chapter 5.7) also mentions the deficiency of data on the oral health status of this adult population and the need for epidemiological research on oral health status of adults.

Most of the epidemiological information of oral health status available on the adult population in Norway is from the Trøndelag and Oslo studies [4,5]. The studies are carried out on a fairly regular basis of approximately 10 years interval. They have shown a marked improvement in oral health over the years [4$6]$. Another study of oral health in adults is one that has regularly followed up dental health status of mili- tary recruits from 1968 [7]. Besides these, there are some studies that target particular population groups, for example the elderly $[8,9]$. These studies have shown that northern Norway had the lowest percentage of the elderly who had their own teeth and the highest proportion of denture users [2]. The latest official reports on dental health states that residents of northern Norway have the poorest oral health and teeth status as compared with the rest of the country. In addition, they are the ones with the least frequent dental visits, most emergency visits to the dentist, and are least satisfied with how quickly they receive treatment when they have acute problems [10]. Based on statistics from municipalities there is an indication that there is a higher risk of poor dental health among indigenous Sami as compared to the indigenous Norwegian population living within the same county [11]. There is however no recent published studies on oral health and underlying determinants among adults in northern Norway generally, and specifically among the indigenous Sami population which are predominantly located in the north. A study from 1988 on dental status of adults from the northern towns of Alta, Honningsvåg, Karasjok and Kautokeino which included 900 adults did not include any information on ethnicity, but results from the study showed that at that time, oral health was poorer in the north when compared with the rest of the country $[12,13]$.

This paper presents results from a pilot study for an epidemiologic oral health survey of adults being planned for northern Norway and specifically for areas with large indigenous Sami populations, the so called SAMINOR 2 study. The SAMINOR project ("Population based study of health and living conditions in areas with both Sami and Norwegian populations") is a population-based study aimed at studying health and 
disease in relation to living conditions among the Sami population and to compare these with the Norwegian population in the same area [14]. The first data collection in the SAMINOR study was carried out in 2003-2004. A second data collection (SAMINOR 2) is being planned for 2012/2013 with focus on 5 major health related issues; Diabetes type II, health service research, use of disability pension, mental health and dental health.

The general aim of this pilot study was to develop and test out methods for the planned epidemiological survey of dental health among adults in northern Norway. Specifically the study was to develop a questionnaire appropriate for the specified study, validate the findings of a clinical examination with and without radiographs, and find out the response rate of the target population group for such a study.

\section{MATERIALS AND METHODS}

\section{Sampling and data collection}

The pilot study was conducted in the municipalities of Nordkapp and Båtsfjord in Finnmark County. These municipalities were chosen for practical reasons; the presence of a functioning public dental clinic in each of these towns and location in the northernmost county of Finnmark, but not part of the geographic area for the main SAMINOR 2 study. Inclusion criteria for the pilot study were residence in these municipalities and age between 18 and 69 years.

Random selection of 100 adults (50 women and 50 men) from each of the municipalities, in total 200, was done based on the Norwegian National Register. The registry provided the names, addresses, year of birth, and gender of those selected.

The 200 persons invited were mailed letters of information explaining the project, including information about a free oral examination as part of the study. They also received questionnaires, consent forms and postage-paid return envelopes. Prior to sending out questionnaires, awareness about the project had been created by the use of local newspapers and local radio broadcasts. Respondents to the questionnaires and consent forms received appointment cards to a free oral examination at the government dental clinic located in their town of residence. The appointment cards were sent by post and included a message that participants could call to change appointment time if time allocated was inconvenient. The oral examinations were carried out from October 2010 to February 2011. One reminder was sent out in January 2011 with the questionnaire included.

\section{Questionnaire}

The questionnaire was aimed at collecting information about oral health status through the use of oral health indicators, oral hygiene habits (past and present), use of and cost spent on dental services, satisfaction with different aspects of available dental service, and self- perceived oral health. The questionnaire had 40 questions. There were questions on ethnicity because the SAMINOR study targets areas where there is a mixture of indigenous Sami and Norwegian population. In addition to questions formulated specifically for this study, some questions were modeled after the oral health study under the HUNT 3 study [15] and some after the Finnmark study of 1988 [12]. Socioeconomic status was measured by questions on education, income and income source. Questions on ethnicity were based on language (own and parents/grandparents), ethnicity of parents, and self-perceived ethnicity. Use of dental services was assessed by questions on regularity of visits and type of dental service (private or public). Regularity was measured by questions on attendance in the last 5 years, how appointments are booked (e.g. regular invitation or when in pain) and how often if regularly invited. Accessibility, costs and satisfaction with dental services were measured by questions on economic hindrances, cost of dental services in the last year, and satisfaction with treatment received, cost, information and geographical distance to dental clinic. Oral health indicators were measured by questions on oral symptoms, earlier diagnosed oral disease, selfperceived oral health status and satisfaction with teeth/oral status. Present oral hygiene behavior was measured by questions on regularity of tooth brushing, use of dental floss, toothpicks, toothpaste, fluoride tablets and fluoride mouth rinses. There were questions about past oral hygiene behavior and parental control of oral hygiene practice (tooth brushing) in childhood.

\section{Oral examination}

Dental status was assessed by clinical and radiological oral examinations using the DMFT (Decayed, Missing, Filled Teeth) and CPITN (Community Periodontal Index of Treatment Needs) indices. The DMFT index measures past and present caries experience and is a summation of all teeth that are filled, carious or extracted due to caries. The CPITN index measures the health status of the periodontium (teeth supporting structures) using a periodontal probe. In measuring the CPITN, the mouth is divided into six (sextants) and a score is recorded for each sextant $(0=$ healthy gingiva, $1=$ bleeding on gentle probing, $2=$ calculus, $3=$ shallow periodontal pocket $4-5 \mathrm{~mm}, 4=$ deep pocket $6 \mathrm{~mm}$ or more). All examinations were carried out by dental nurses/hygienist working at the clinics under artificial illumination (fiber optic light) using mouth mirrors, probes and oral X-ray units. There was a calibration session with all the examiners prior to the commencement of the study. Clinical measures of tooth status, caries experience and periodontal disease were recorded using standard WHO criteria for basic oral surveys [16]. There was in addition a radiological examination consisting of bilateral-bitewing radiographs. Recordings were made manually. Mean DMFT were calculated with and without radiographs and compared. 
Periodontal health status was assessed by the use of a standard CPI probe (WHO) to measure the community periodontal index of treatment needs (CPITN). Use of removable dentures was also recorded.

\section{Statistical analysis}

All data management and analyses were performed using the SPSS software (version 16). Bivariate analysis was carried out with cross tables and chi-square test. Bland Altman scatter chart was used to investigate agreements between results of DMFT with and without radiographs. The following variables were dichotomized in the analysis due to the low sample size; satisfaction with teeth (satisfaction measured on a scale of 1 to 5 , where 1 was least satisfied and 5 most satisfied; dichotomized in 1-2 not satisfied, 3-5 satisfied), experience with dental pain in the past year (answer alternatives were; never or seldom $=$ no pain, few times, rather often or often $=$ pain), satisfaction with different aspects of dental services (scale of 1 to 6 where 1 was most dissatisfied and 6 was most satisfied; dichotomized in 1-3 not satisfied, 4-6 satisfied), self-perceived oral health and regularity of dental visit. The question on self-perceived oral health had 4 answer alternatives; poor/bad, not so good, good and very good. In the data analysis the variable was dichotomized to poor/bad or good. T-test was carried out for DMFT/ CPITN and some variables from the questionnaire.

\section{Ethics}

The study was approved by the Regional Committee for Medical and Health Research Ethics-Northern Norway. All participants were invited to join the study by completing and returning a consent form.

\section{RESULTS}

\section{Response rate and basic characteristics}

Of the 200 men and women invited, 34\% ( $n=68)$ answered and returned the questionnaires, $27 \%(n=53)$ showed up for the oral examination, and $8 \%(n=15)$ answered the questionnaire but did not attend the oral examination (Table 1). Only $6 \%$ of the participants were aged between 18 and 29 years. Linear by linear association Chi square test showed a higher response rate for older age groups $(p=0.08$, Table 2$)$. Mean age of men that participated was 48 yrs, for women 45.3 yrs. There was no significant difference in age between men and women $(\mathrm{p}=0.19)$. Response rate was highest among women above forty years old (37\%) and lowest among men under forty years (12\%) (Figure 1).

\section{Response rate to the questionnaire}

There was $100 \%$ response rate among participants to the question on present oral hygiene habits. The questions on how much dental treatment had cost in the last year and satisfaction with different aspects of available dental service had response rates of $97 \%$ and $92 \%$ respectively. Ninety six percent responded to the ques-
Table 1. Basic characteristics of participants $(n=68)$.

\begin{tabular}{lrr}
\hline Characteristics & $n$ & $\%$ \\
\hline Age (years) & & \\
$18-29$ & 4 & 6 \\
$30-39$ & 16 & 23 \\
$40-49$ & 17 & 25 \\
$50-59$ & 8 & 12 \\
$60-70$ & 23 & 34 \\
Gender & & \\
$\quad$ Men & 30 & 44 \\
$\quad$ Women & 38 & 56 \\
Geographical area of residence & & \\
$\quad$ Nordkapp & 39 & 57 \\
$\quad$ Båtsfjørd & 29 & 43 \\
Oral examination & & \\
$\quad$ Yes & 53 & 78 \\
$\quad$ No & 15 & 22 \\
\hline
\end{tabular}

Table 2. Response rate in different age groups.

\begin{tabular}{lcc}
\hline Age & Total invited (n) & Participants, \% (n) \\
\hline $18-29$ & 27 & $15 \%(4)$ \\
$30-39$ & 41 & $39 \%(16)$ \\
$40-49$ & 49 & $35 \%(17)$ \\
$50-59$ & 30 & $27 \%(8)$ \\
$60-70$ & 53 & $43 \%(23)$ \\
\hline
\end{tabular}

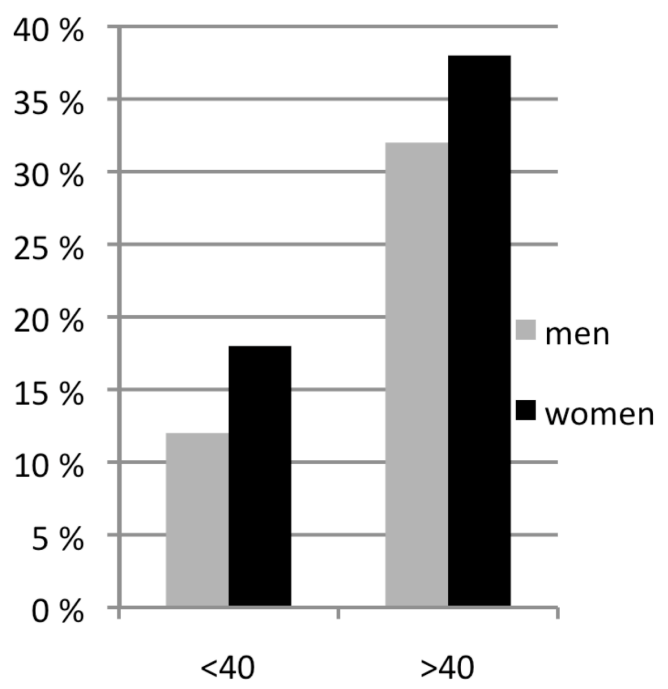

Figure 1. Distribution of male and female respondents below and above 40 years.

tion about visiting a dental clinic at least once a year in the last 5 years, but $32 \%$ did not respond to questions on how often there were invited for an oral check-up if they were regularly invited. The questions on how long it took to get an appointment the last time they needed to see a dentist and compliance to treatment recommended were left unanswered by $19 \%$ and $20 \%$ 
Table 3A. Questionnaire response for oral health indicators $(\mathrm{n}=68)$.

\begin{tabular}{lrr}
\hline Category & $\mathrm{n}$ & $\%$ \\
\hline Self perceived oral health & & \\
Poor & 27 & 40 \\
Good & 38 & 56 \\
Missing & 3 & 4 \\
Oral pain in the last year & & \\
No & 39 & 57 \\
Yes & 26 & 38 \\
Missing & 3 & 4 \\
Earlier diagnosis periodontal disease & & \\
yes & 18 & 26 \\
No/don't know & 36 & 53 \\
Missing & 14 & 21 \\
Satisfaction with teeth & & \\
$\quad$ Not satisfied & 15 & 22 \\
Satisfied & 52 & 76 \\
$\quad$ Missing & 1 & 2 \\
\hline
\end{tabular}

Table 3B. Questionnaire response for questions on use of dental services, level of satisfaction with accessibility and costs of dental services $(n=68)$.

\begin{tabular}{|c|c|c|}
\hline Category & $\mathrm{n}$ & $\%$ \\
\hline \multicolumn{3}{|l|}{ Dental visit yearly in last 5 years } \\
\hline Yes & 33 & 48 \\
\hline No & 33 & 48 \\
\hline Missing & 2 & 3 \\
\hline \multicolumn{3}{|l|}{ Use of dental services } \\
\hline Regularly invited by dental clinic & 35 & 51 \\
\hline Regular self -registration for dental check-ups & 6 & 9 \\
\hline Dental visit only when in pain or lost a filling & 19 & 28 \\
\hline Does not visit the dentist often & 8 & 12 \\
\hline Missing & 0 & 0 \\
\hline \multicolumn{3}{|l|}{ Postponed dental visit due to financial constraints } \\
\hline Yes & 20 & 29 \\
\hline No & 45 & 66 \\
\hline Missing & 3 & 4 \\
\hline \multicolumn{3}{|l|}{ Satisfaction with dental services: } \\
\hline \multicolumn{3}{|l|}{ Geographic distance to dental clinic } \\
\hline Yes (satisfied) & 56 & 82 \\
\hline No (not satisfied) & 2 & 3 \\
\hline "I don’t know" & 6 & 9 \\
\hline Missing & 4 & 6 \\
\hline \multicolumn{3}{|l|}{ Advice and treatment received } \\
\hline Yes & 52 & 77 \\
\hline No & 3 & 4 \\
\hline "I don’t know" & 10 & 15 \\
\hline Missing & 3 & 4 \\
\hline \multicolumn{3}{|l|}{ Cost of dental expenses } \\
\hline Yes & 31 & 46 \\
\hline No & 24 & 35 \\
\hline "I don’t know" & 9 & 13 \\
\hline Missing & 4 & 6 \\
\hline
\end{tabular}

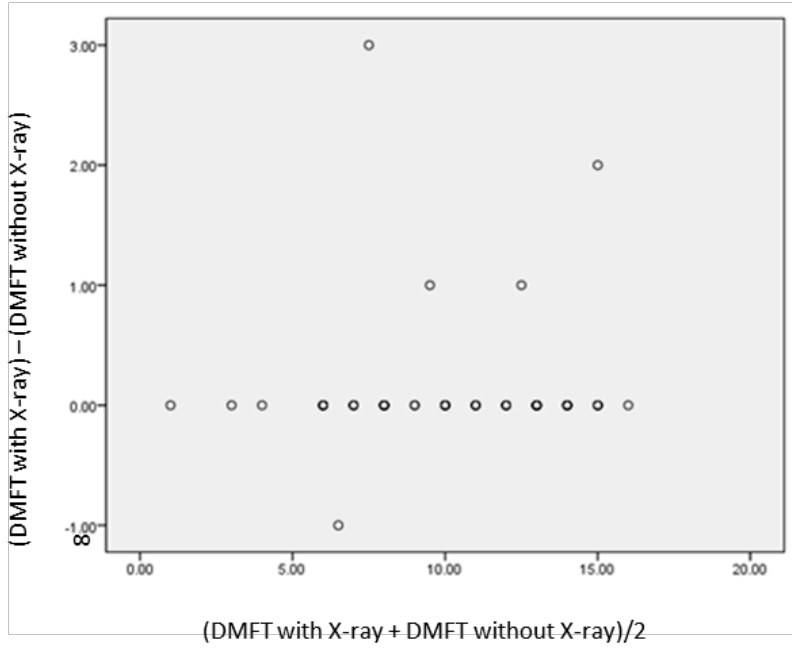

Figure 2. Bland Altman plot for DMFT with and without radiographs.

respectively. Thirty one percent left unanswered the questions on how long dental treatment took in total (including travel and waiting time). Response rate to the question on oral hygiene practice in childhood (10 years) was $98 \%$, and $75 \%$ indicated that they did not have children less than 12 years old living at home.

Table $3 \mathrm{~A}$ presents oral health indicators and table $3 \mathrm{~B}$ presents use of, and satisfaction with available dental services as reported by respondents to the questionnaire. Twenty eight percent attend a dental clinic only when they have pain or have lost a filling and $22 \%$ had not complied with the recommended treatment due to the treatment costs. The most used oral hygiene product was the toothbrush (95\% indicated regular daily use).

\section{Results from oral examination and comparisons with questionnaire data}

Oral health status observed during the oral examination was measured by the DMFT and CPITN indices. Mean DMFT with radiograph was 13.4 and without radiographs 13.3 (t-test, $\mathrm{p}=0.14$ ). A CPITN score of 0 for the highest scoring sextant was recorded for $13 \%$ of participants, $0.5 \%$ had scores of 1 or $2,36 \%$ had scores of 3 or 4 . One participant was edentulous and used full upper and lower dentures and $15 \%(n=8)$ had removable partial dentures.

A Bland Altman plot indicated good agreement between DMFT scores measured with or without radiographs (Figure 2).

The findings on regularity of dental visit in the last 5 years, and some of the findings on oral health indicators (satisfaction with teeth, dental pain in the last year, self-perceived oral health and earlier diagnosis of gum disease) were tested against findings from the oral examination (DMFT and/or CPITN). These are presented in tables 4 and 5. The number of participants (n) in table 4 and 5 are different from tables $3 \mathrm{~A}$ and $3 \mathrm{~B}$ 
Table 4. Mean DMF ( $95 \%$ confidence interval) by selected variables from the questionnaire ( $\mathrm{n}=53)$.

\begin{tabular}{lccccc}
\hline & \multicolumn{3}{c}{ Yes } & & No \\
\cline { 2 - 5 } Variable & number & Mean DMFT (CI) & number & Mean DMFT (CI) & p-value \\
\hline Satisfied with teeth & 42 & $12.8(11.3-14.3)$ & 9 & $15.0(12.9-17.1)$ & $\mathrm{P}=0.8$ \\
Regular visits (yearly in last 5yrs) & 28 & $13.6(12.0-15.2)$ & 24 & $12.4(10.8-14.0)$ & $\mathrm{P}=0.8$ \\
Dental pain in the last year & 19 & $11.9(10.1-13.6)$ & 32 & $13.7(12.2-15.2)$ & $\mathrm{P}=0.6$ \\
Self-perceived oral health; good & 30 & $13.2(11.5-14.9)$ & 21 & $12.9(11.4-14.4)$ & $\mathrm{P}=0.2$ \\
\hline
\end{tabular}

Table 5. Mean CPITN ( $95 \%$ confidence interval) by selected variables from the questionnaire $(\mathrm{n}=53)$.

\begin{tabular}{|c|c|c|c|c|c|}
\hline \multirow[b]{2}{*}{ Variable } & \multicolumn{2}{|r|}{ Yes } & \multicolumn{2}{|r|}{ No } & \multirow[b]{2}{*}{ p-value } \\
\hline & number & Mean CPITN (CI) & number & Mean CPITN (CI) & \\
\hline Satisfied with teeth & 42 & $2.1(1.8-2.4)$ & 9 & $2.0(1.6-2.4)$ & $\mathrm{P}=0.3$ \\
\hline Regular visits (yearly in last 5 yrs) & 28 & $2.1(1.8-2.4)$ & 24 & $2.1(1.8-2.4)$ & $\mathrm{P}=0.8$ \\
\hline Dental pain in last year & 19 & $2.1(1.8-2.4)$ & 32 & $2.2(1.9-2.5)$ & $\mathrm{P}=0.9$ \\
\hline Self-perceived oral health; good & 30 & $2.0(1.7-2.3)$ & 21 & $2.2(1.9-2.5)$ & $\mathrm{P}=0.5$ \\
\hline Earlier diagnosis of gum disease & 11 & $2.7(2.4-2.9)$ & 41 & $1.9(1.6-2.2)$ & $\mathrm{P}=0.9$ \\
\hline
\end{tabular}

because not all who answered the questionnaire $(n=68)$ showed up for the oral examination $(n=53)$. T test on mean DMFT and mean CPITN of highest scoring sextant showed no significant differences between; those satisfied and those not satisfied with teeth, those who have been attending regularly in the last 5 years and those who have not been attending regularly, those who had dental pain in the last year and those who have not, and those who consider their oral health as good and those who did not (Tables 3 and 4). No significant difference was registered in CPITN values for those who have had an earlier diagnosis of gum disease (periodontitis) and those who had not.

\section{DISCUSSION}

The purpose of this study was to develop and test out methods for an oral epidemiologic study of adults in northern Norway under the SAMINOR study. The main finding was a low response rate which casts doubts on the feasibility of reproducing the study design on a large scale. The results obtained cannot be used to make any conclusions about oral health in the populations studied because of the low response rate, but that was not the primary aim of the study.

Participants were randomly selected in order to ensure a proper representation of the population. The low response rate in spite of media generated awareness (through local newspaper and radio), was unexpected and difficult to explain. It raises a question of whether there is a lack of awareness of the importance of dental health in these communities or, whether there is a lack of interest in dental health. A study aimed at answering these questions by identifying attitudes to, and awareness of different aspects of dental health in northern Norway is recommended. Issues that should be addressed include intrinsic motivation to maintain or improve oral state, awareness of functional and social/aesthetic consequences of a poor dental status, awareness of possible consequences of poor oral health on general health, and suspicion/trust regarding the motives of dental health care professionals $[17,18]$. It will be important to include questions on ethnicity in such a survey to identify cultural differences in attitudes.

For the main study (SAMINOR 2), a better response rate is required. In 2003/4 when the first data collection was carried out for the SAMINOR study, oral health was not included and response rate was $60.6 \%$ $(n=16865)$ [14]. Variables measured in that study included height, weight, pulse recordings and blood pressure. Blood samples were taken and blood cholesterol, triglycerides, glucose and iron levels were measured. Participants received letters informing them of the test results and recommendations to see a doctor for those with unhealthy results. The inclusion of oral health as part of a more comprehensive health examination could possibly enhance response rate for the oral health survey. An alternative way of improving the response rate could be by collecting oral health data from adult patients that attend the local clinics in the SAMINOR areas through collaboration with these clinics. The problem with this method would be a selection bias; data collected would be from those that normally attend dental clinics and not from the total population. Collecting data from those who do not normally attend dental clinics is a challenge and as the pilot study showed, even the prospect of a free dental check-up was not enough to get a good response rate.

Of those that responded, $56 \%$ were women and 
$71 \%$ were over 40 years old. The same pattern was observed in the SAMINOR studies (women and older people were more responsive). Younger people are often less interested in answering questionnaires and this was confirmed by the fact that only $15 \%(n=4)$ of the invited $(n=27)$ in the age group 18 and 29 years participated. Generally, many in this age group are students who live away from home and it is possible that some of those invited in this age group did not respond because they are living and studying in other towns. To get satisfactory response rate it is recommended that the main study should target adults aged 40 to 70 years. However, appropriate methods for assessing dental health for the younger population should be developed.

The question directed at those who were regularly invited for a dental check-up on how often they were invited can be omitted in the main study because the issue of regularity is well covered by the questions on whether there has been dental visits at least once a year in the last five years, and how appointments for dental visits are made (regular invitation, regular selfregistration or appointments only when in pain or lost fillings). The questions on how long it took to get an appointment last time at the dentist, and if cost affected compliance to treatment recommended were left unanswered by $19 \%$ and $21 \%$. The information they would have supplied (an indication of adequacy and affordability of available dental service) are provided by other questions (the question on costs and satisfaction with different aspects of available dental service), and these questions can therefore be omitted.

The question about present oral hygiene habits was answered by everyone and is an important pointer to oral health. Questions in relation to oral health, cost of dental service and satisfaction with available dental services are highly relevant in an oral health survey and were answered by more than 90 percent, an indication that they were well understood. The questionnaire did not include a question on how many teeth were in the mouth because the survey included an oral examination. It would be important to include this question in subsequent studies to provide valuable information in the eventuality that the participant does not show up for an oral exam (or if there is no oral examination).

Nearly everyone responded to the question on oral hygiene practice in childhood but most participants $(75 \%)$ indicated that they did not have children below the age of 12 at home. In spite of this, the inclusion of questions on present parental attitude to oral health and oral hygiene habit is highly recommended. Questions on teeth alignment and use of orthodontist were mostly left unanswered and should be omitted from the main study.

The percentage that have regular dental visits (at least once a year in the last 5 years) and percentage that had been to a dentist within the last year was low compared to a nation-wide study in 2004 that found $69 \%$ had been to the dentist at least once a year in the last 5 years, and $78 \%$ had been to a dentist within the last year [19]. Although this findings support the latest official reports on dental health which claims that residents of northern Norway are the ones with the least frequent dental visits [10], the external validity of the results are questionable due to low response rate. A nation-wide study of adults in 2004 [20] found that $68 \%$ considered their oral health as good while in this study $56 \%$ did so. The findings on satisfaction with treatment cost, postponement of dental visit and lack of compliance to recommended treatment due to treatment costs indicate that treatment cost could be a factor contributing to the relatively lower attendance rate reported [10] in this part of the country. Those who indicated "Daily use of a toothbrush" $(96 \%)$ were similar to results from a nation-wide study on oral health habits of adults (97\%) [21].

The oral examination was both clinical and radiological. The clinical examination was based on WHO guidelines with focus on caries experience and periodontal disease [16]. The findings from the comparison of mean DMFT with and without radiographs support the view that radiographs are not necessary for oral epidemiological surveys that study trends rather than prevalence of caries [22].

Periodontal health status was assessed by the community periodontal index of treatment needs (CPITN) [23].

Mean DMFT for the study sample was 13.3. The Oslo study found mean DMFT for 35-year-olds to be 11.7 in 2003 [24], and 14.6 for 35-44-year-olds in the Trøndelag study in 2006 [6]. Eleven percent had CPITN scores of 4 (at least one pocket $>$ or $=6 \mathrm{~mm}$ ). A study on periodontal health status of 35 year olds in Oslo showed a decrease in the proportion of persons with CPITN scores of 4 from $21.9 \%$ in 1984 to $8.1 \%$ in 2003 [25]. It is difficult to compare the DMFT and CPITN values from this study with the studies from Oslo and Trøndelag because of the small sample size and wide age range in this study.

There were several questions with more than two answer alternatives because of the subjective nature of the questions and it was necessary to dichotomize these variables prior to data analysis because of low sample size. However, it is recommended that these questions are presented with more than two answer alternatives in the main study. The low sample size could account for the absence of significant difference in mean DMFT and CPITN scores for the variables tested from the questionnaire due to low statistical power. The lack of observed significance could also be due to other reasons for example, differences in personal expectations/definition of what a healthy oral status is. The subjective nature of findings from a questionnaire makes it important to include a physical examination (which is more objective and factual) in an oral epidemiologic study.

In conclusion, the pilot study has tested out tools and methods for a larger oral health survey in the north 
of Norway and revealed that carrying out such a survey in isolation in this part of the country can result in low response rate. There is a need for oral health epidemiological studies in these parts of the country but also a need to develop strategies to ensure good response rate while planning for such studies. While a radiological examination can be excluded in subsequent epidemiologic studies for describing oral health status in northern Norway, it is important to have an appropriately designed questionnaire and an oral examination.

\section{ACKNOWLEDGEMENTS}

The Ministry of Health provided financial support for this study. The authors would like to thank Professor Harald Eriksen (Institute for Clinical Odontology, University of Tromsø) and statistician Marita Melhus (Centre for Sami Health Research, University of Tromsø) for the professional advice and support they provided. We would also like to thank the Director of dental services for Finnmark County, Torill Lauritsen, the dental clinics at Båtsfjord and Nordkapp for their participation and Lena Soini Store, Bente Vatndal, and Ann Karin Olsen who conducted the oral examinations.

\section{REFERENCES}

1. Gift HC, Atchison KA. Oral health, health, and health-related quality of life. Med Care 1995; 33 (11 Suppl): NS57-77.

2. Folkehelseinstituttet. Tannhelsestatus i Norge. En oppsummering av eksisterende kunnskap. 2009. Rapport 2009:5.

3. Stortingsmelding nr. 35 (2006-2007) Tilgjengelighet, kompetanse og sosial utjevning - Framtidas tannhelsetjenester. Helse- og omsorgsdepartementet, 2006-2007.

4. Schuller AA, Holst D. Changes in the oral health of adults from Trøndelag, Norway, 1973-1983-1994. Community Dent Oral Epidemiol 1998; 26 (3): 201-8.

5. Skudutyte-Rysstad R. Studies on dental diseases among 35-year-olds in Oslo, Norway, 1973-2003. Thesis, Faculty of Dentistry, University of Oslo, 2009.

6. Holst D, Schuller AA, Dahl K. Tannhelseutviklingen i den voksne befolkningen i Nord-Trøndelag fra 1973 til 2006. Nor Tannlegeforen Tid 2007; 117: 804-11.

7. Asmyhr O, Grytten L, Grytten J. Changing trends in caries experience among male military recruits in Norway. Community Dent Oral Epidemiol 1994; 22: 206-7.

8. Henriksen BM. Oral health among the elderly in Norway. A descriptive epidemiological study. Swed Dent $J$ Suppl 2003 (162): 1-56.

9. Ekbäck G, et al. Variation in subjective oral health indicators of 65-year-olds in Norway and Sweden. Acta Odontol Scand 2009; 67: 222-32.

10. Ekornrud T, Jensen A. Tannhelse. Personell og kostnader, tannhelsetilstand og tannlegebesøk. Oslo: Statistisk Sentralbyrå Rapport 29/2010.

11. Fylkestannlegen i Finnmark (The director for dental services, Finnmark County). Arsrapport - Tannhelse (The annual dental report). 2006, Finnmark.

12. Holst D. Levekår og tannhelse i Finnmark. Oslo: Universitetet i Oslo, 1988.

13. Holst D, Skau I. Tenner og tannstatus i den voksne befolkning i Norge: Hvor stor er den sosiale ulikheten? Nor Tannlegeforen Tid 2010; 120: 164-9.

14. Lund E, et al. Population based study of health and living conditions in areas with both Sami and Norwegian populations - the SAMINOR study. Int J Circumpolar Health 2007; 66 (2): 113-28.

15. Helseundersøkelsen i Nord-Trondelag, HUNT 3. http://www.ntnu.no/hunt/skjema.

16. WHO. Oral Health surveys. Basic Methods, 4th edn. WHO, 1997.

17. Stockwell RG, Banting D. The dental attitudes questionnaire: an instrument for assessing oral health care attitudes. Can Psychol 1984. 25: 2a-473.

18. Bos A, Hoogstraten J, Prahl-Andersen B. A comparison of dental health care attitudes in the Netherlands in 1985, 1995, and 2001. Community Dent Oral Epidemiol 2003; 31 (3): 207-12.

19. Holst D, Grytten J, Skau I. Den voksne befolknings bruk av tannhelsetjenester i Norge i 2004. Nor Tannlegeforen Tid 2005; 115: 212-6.

20. Holst D, Skau I, Grytten J. Egenvurdert tannhelse, generell helse og tannstatus i den voksne befolkning i Norge i 2004 (Self assessment of oral health, general health and dental status in national sample of adult Norwegians in 2004). Nor Tannlegeforen Tid 2005; 115: 576-80.

21. Molund L, et al. Predictorer for oral hygieneatferd i den voksne norske befolkningen. Nor Tannlegeforen Tid 2009; 119: 298-302.

22. Bloemendal E, de Vet HC, Bouter LM. The value of bitewing radiographs in epidemiological caries research: a systematic review of the literature. $J$ Dent 2004; 32 (4): 255-64. 
23. Cutress TW, Ainamo J, Sardo-Infirri J. The community periodontal index of treatment needs (CPITN) procedure for population groups and individuals. Int Dent $J$ 1987; 37 (4): 222-33.

24. Skudutyte-Rysstad R, Eriksen HM. Changes in caries experience among 35-year-old Oslo citizens, 19732003. Acta Odontol Scand 2007; 65 (2): $72-7$.

25. Skudutyte-Rysstad R, Eriksen HM, Hansen BF. Trends in periodontal health among 35-year-olds in Oslo, 1973-2003. J Clin Periodontol 2007; 34 (10): 867-72. 